\title{
Management of Tail Affections in Cows and Buffaloes
}

\author{
Sandhya Rani Dasari ${ }^{1}$, Aruna Maramulla ${ }^{2}$, Samskruthi Guddeti ${ }^{3}$ and Sudhakar Deeti ${ }^{4}$ \\ ${ }^{1}$ Department of Veterinary Medicine, Jagithyal, Telangana, India \\ ${ }^{2}$ Department of Veterinary Medicine, Godavarikhani, Telangana, India \\ ${ }^{3}$ Department of Veterinary Medicine, Nizamabad, Telangana, India \\ ${ }^{4}$ Department of Biological Sciences, Macquarie University, Sydney, NSW 2109, Australia
}

*Corresponding author

\section{A B S T R A C T}

Keywords

Tail gangrene,

Necrosis, Epidural

Anesthesia,

Amputation

Article Info

Accepted:

12 May 2021

Available Online:

10 June 2021
Tail affection is a common occurrence in Indian domestic livestock. A common perception is that tail affection are prone to various affections like necrosis, gangrene and wounds, and if not treated, lead to the animal's death. Most of these affections do not respond to routine medical management and demand amputation of the tail. Here we conducted a surgical amputation of the tail to cure the affections in buffaloes and cows' between the ages of 4 to 6 years old. After the surgical intervention, the tail necrosis, gangrene, and wound of the infected animals were successfully managed and followed by conservative therapy. The clinical case studies concluded that the tail affections healed without complications with the surgical and medicinal approach.

\section{Introduction}

Tails are part of the evolutionary package for many animals. When an animal raises its tail like a flag and swishes it from side to side, it is a classic sign that they are about to calve. Animals use their tails for different functions to communicate strong emotions such as agitation, balance, gripping, attracting mates, annoyance and anger, and happiness (Fisher PG, 2006). As with other animals, the tail wagging of cows and buffaloes could indicate vital signs in the livestock. They lift their tail slightly during oestrus and use the tail head for heat detection aids such as tail paint and heat mount detectors. The tail physically lifts during urination and defecation. The tail prevents the animal from the ectoparasites nesting on its body or other irritations (Alam et al., 2010). When calves and cows play or run and during crucial signalling devices, cows often wag their tails as a threat (Salib and Farghali, 2016). Recurrent tail affections are a significant cause of morbidity and 
mortality of livestock. It is a significant challenge to manage clinically. Due to the tail's normal anatomy and physiology, a wide variety of lethal bacterial affections can cause necrosis, gangrene and wounds to it (Nuss and Fiest, 2011). Inflammation and necrosis on the tail may occur in any species. Still, buffaloes appear to be more predisposed and it seems to be a significant source of a substantial reduction in well-being (Singh and Kumar, 2001). Whereas the Tail gangrene in buffaloes and cows is common, several possible causes can be identified, such as Corynebacterium bovis, deficiency of fatty acids, and microfilaria (George et al., 1970). The infected organisms may colonize the wound which could result in local or systemic affection of the tail. If we neglect these tail affections, it may lead to the spread of disease to the spinal cord, decrease milk production and in rare cases, cause animal death. It has a significant impact on the economic welfare of a farmer.

Anecdotal and various scientific reports are stated that tail affections are most prevalent in Indian livestock during wet seasons due to specific bacteria infecting the tail. There are many traditional methods in practice to treat tail affections in livestock.

The most immediate treatment for any animal with tail affection is to vaccinate it against tetanus. In addition, it has been common practice to amputate tail affections because this might prevent the progression of the disease up the tail leading to the ultimate death of the animal. Treatment with Antibiotic and anti-inflammatory agents is likely to cause relief of the pain and assist healing after the amputation of the tail.

To understand etiology and assess the importance of tail tip necrosis and gangrene, we studied similar surgical amputation procedure here in buffaloes and cows. In this study, surgical tail amputation was assessed in anaseptic condition with epidural anaesthesia followed by horizontal mattress sutures.

\section{Case history}

We have examined five animals in early 2020 - 2021, two buffaloes and three cows, weighing around 400 to $600 \mathrm{kgs}$. All the animals were aged 4 to 6 years with various tail affections and were observed for necrosis, gangrene, and wound on the tail. Interestingly, all the animals did not have previous history of tail affections. One cow had gangrene at the middle to the tip of the tail (Fig 1). In two Holstein Friesian (HF) cows, one had necrosis and gangrene at the middle of the tail (Fig 6). On referral at clinical examination, including inspection and routine physical evaluation, except the lesion on the tail, the cows were otherwise healthy (Dasari and Marumulla, 2021). Diagnosis of the tail affections was made based on gross lesions. The two Buffaloes have been reported with necrosis at the tip of the tail (Fig5 and 7) as it was common mainly in buffaloes. As the farmer reported, the tip of the tail was initially swollen and was followed by signs of inflammation in about a week in beef cattle. Whereas another HF cow had a wound at the tip of her tail (Fig 8).

\section{Materials and Methods}

In all cases, animal conditions were discussed with the owners and a decision was made to amputate the affected parts on the tail tip.

For all the individual animals food was withheld eight hours before surgery. Prior to surgery, individual animals were weighed and sedated with the Xylazine Hydrochloride (0.05mg $/ \mathrm{KgB}$. wt.) followed by an epidural block using $10 \mathrm{ml}$ of $2 \%$ lignocaine Hydrochloride to calm the animals. Xylazine helped handle the animal for injection of the 
epidural anaesthesia for desensitization of tail and subsequent amputation procedures. The epidural block facilitated easy restraint for standing positions. Following injection, the animals were left undisturbed and monitored. The tail amputation procedure was performed when the animal was in a standing position by locating the first intercoccygeal space with the tip of a finger when the tail was manipulated up and down, with the other hand moving the tail in a pump-like a manner. The injection site was clipped and aseptically prepared using a disinfectant solution and then introduced a $18 \mathrm{G}$ hypodermic needle was at an angle of $45^{\circ}$ to the depth of about 0.5 to 1 inch to enter the vertebral canal. During epidural anaesthesia correct position of needle can be checked by the hanging drop technique, which can be performed by placing few drops of Lignocaine into the needle hub. If the needle enters the correct position, the drop of lignocaine is observed to be aspirated under the effect of negative pressure in the epidural space. Later, $10 \mathrm{ml}$ of $2 \%$ Lignocaine hydrochloride administered slowly to achieve caudal desensitization of the tail (Dasari and Marumulla, 2021). The desensitization of the animal can be tested by poking various parts of the tail with a needle after the injection of epidural anesthesia. A tourniquet was applied at the base of the tail. The exact point of disarticulation was determined by palpation. After that, the site was clipped and cleaned with disinfectant solution.

A V-shaped incision creates dorsal and ventral skin flaps that are longer than the desired tail length. The incision needs to be made just distal to the desired intervertebral space. Two lateral and middle coccygeal arteries are ligated using chromic catgut No. 3 during operation (Fig. 2). The hemorrhage was checked by releasing tourniquet $\&$ bleeding points if they were ligatured or tornised with hemostatic forceps. Then disarticulated the tail at actual site (Fig. 3). The excessive skin was trimmed for perfect apposition of the skin edges. The skin flaps were sutured by horizontal mattress using No. 2 braided silk(Fig.4). After antiseptic dressing, the tail was protected with a bandage. Post-surgery, surgical wounds were dressed up every day and Himax ointment applied topically on the wound for up to 16-18 days. After that, the sutures were removed carefully.

\section{Results and Discussion}

The primary purpose of this study was to assess the identical procedure of surgical tail amputation effect in buffaloes and cows. Surgeries were conducted on animals and all the animals recovered without any complications (Figure 9). In the three weeks, all the animals were cured along with the surgical wounds. In addition, this study also has shown the general importance of surgical amputation and post-medicinal usage for tail affections.

\section{Management of tail affections}

\section{Necrosis}

In the current study, two buffaloes (Fig 5 and 7) and suffering from tail necrosis were did not respond to medical treatment, so surgical treatment was preferred. Post-surgery, the animals were treated with Ceftriaxone @10 mg/kg B. wt. I/M, Meloxicam @0.5mg /kg B. wt.I/M, Histanil @10ml I/M, Beekom-L@10 $\mathrm{mll} / \mathrm{M}$ for 5 days. Animals recovered on the $16^{\text {th }}$ day after Surgery (Table 1 ).

A variety of reasons causes tail necrosis. Earlier studies reported that slatted floors play a role in the development of tail necrosis (Madsen and Nielsen, 1985). Mouldy roughages containing mycotoxins also cause necrosis and gangrene of the extremities, including tail tip necrosis in cattle and buffaloes (Fowler, 2010, Khamis et al., 2002, Dandapat et al., 2011). 
Table.1 The table shows the design of tail amputation case stidues in buffaloes and cows.

\begin{tabular}{|c|c|c|}
\hline Condition of animal & Treatment Followed & Remarks \\
\hline $\begin{array}{l}\text { Buffalo had a necrosis at the tip } \\
\text { of the tail }(\mathrm{N}=2)\end{array}$ & $\begin{array}{c}\text { Amputation of the tail at lower } \\
\text { third of tail. Given Ceftriaxone } \\
\text { @ 10mg/kgB.wt. I/M, Meloxicam } \\
\text { @ } 0.5 \mathrm{mg} / \mathrm{kg} \mathrm{B} . w t . \mathrm{I} / \mathrm{M} \text {, Histanil } \\
@ 10 \mathrm{ml} / \mathrm{M}, \text {, Beekom-L } \\
\text { @10mlI/M for } 5 \text { days. }\end{array}$ & $\begin{array}{l}\text { Animal showed uneventful } \\
\text { recovery without any lesions }\end{array}$ \\
\hline $\begin{array}{c}\text { Cow had gangrene at middle of } \\
\text { the tail }(\mathrm{N}=1)\end{array}$ & $\begin{array}{l}\text { Amputation of the tail at the } \\
\text { middle of the tail. Given Parentral } \\
\text { Dicrysticin @ } 5 \mathrm{gms} \\
\text { I/M,Meloxicam } \\
\text { @ 12mlI/M,Histanil @ } 10 \mathrm{ml} / \mathrm{M} \text {, } \\
\text { Rumeric 10I/M for } 5 \text { days }\end{array}$ & $\begin{array}{c}\text { The animal showed } \\
\text { uneventful recovery without } \\
\text { any lesions }\end{array}$ \\
\hline $\begin{array}{c}\text { Holstein Friesian cow had } \\
\text { necrosis and gangrene at middle } \\
\text { of the tail }(\mathrm{N}=1)\end{array}$ & $\begin{array}{l}\text { Amputation of the tail at middle of } \\
\text { the tail. Given Parentral } \\
\text { Dicrysticin @ } 5 \mathrm{gms} \text { //M, } \\
\text { Meloxicam } 12 \mathrm{ml} \mathrm{I} / \mathrm{M} \text {, Rumeric } \\
\text { @10 ml I/M, Histanil @ } 10 \mathrm{ml} \mathrm{I} / \mathrm{M} \\
\text { for } 5 \text { days }\end{array}$ & $\begin{array}{l}\text { Animal showed uneventful } \\
\text { recovery without any lesions }\end{array}$ \\
\hline $\begin{array}{l}\text { Holstein Friesian cow had } \\
\text { wound at the tip of the tail } \\
\qquad(\mathrm{N}=1)\end{array}$ & $\begin{array}{l}\text { Amputation of the tail. Given } \\
\text { Ceftriaxone @ } 10 \mathrm{mg} / \mathrm{Kg} \mathrm{B} . \mathrm{Wt} \text {, } \\
\text { Meloxicam @ } 10 \mathrm{ml} / \mathrm{M} \text {, } \\
\text { Nurocare } 10 \mathrm{ml} \mathrm{I} / \mathrm{M} \text { for } 5 \text { days }\end{array}$ & $\begin{array}{l}\text { Animal showed uneventful } \\
\text { recovery without any lesions }\end{array}$ \\
\hline
\end{tabular}


Fig.1 Gangrene in Cow

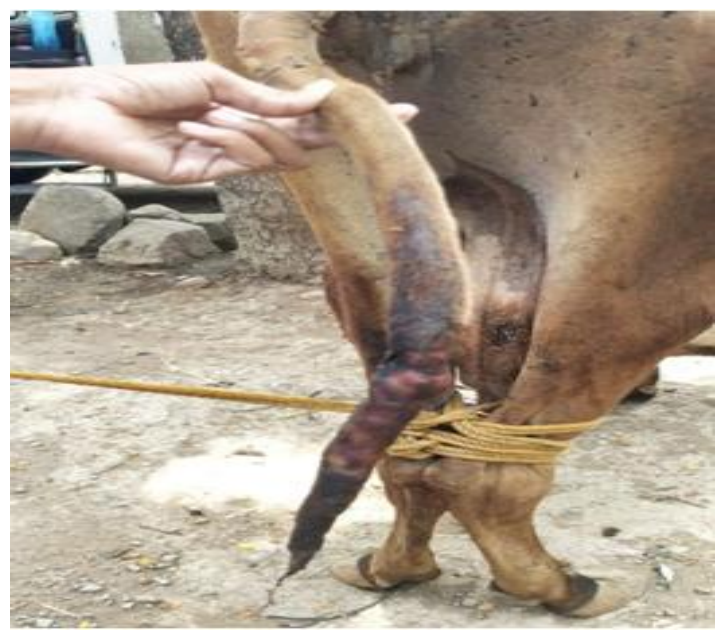

Fig.3 Disarticulation of tail in cows

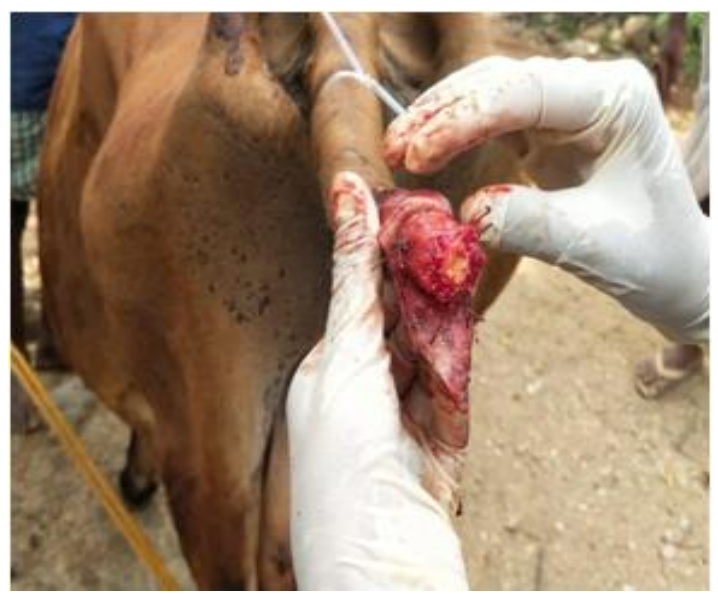

Fig.2 Ligation of arteries in a cow

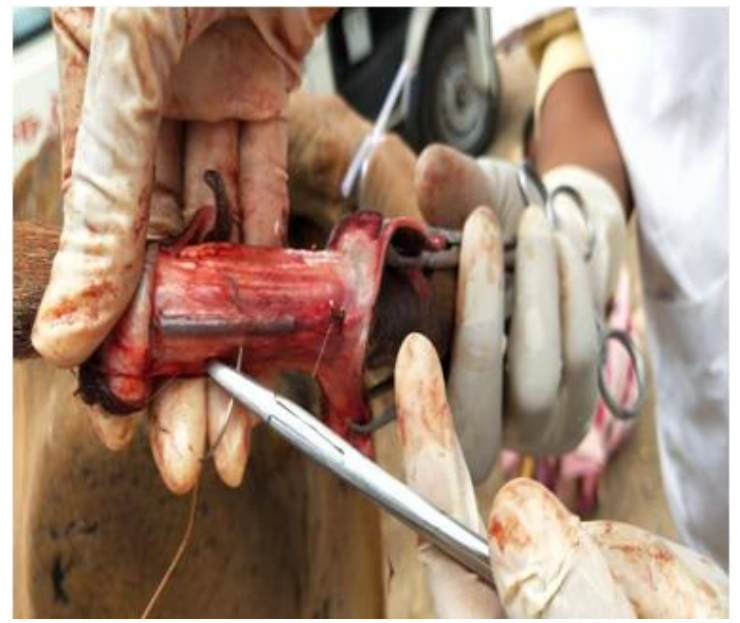

Fig.4 Horizontal mattress sutures were applied

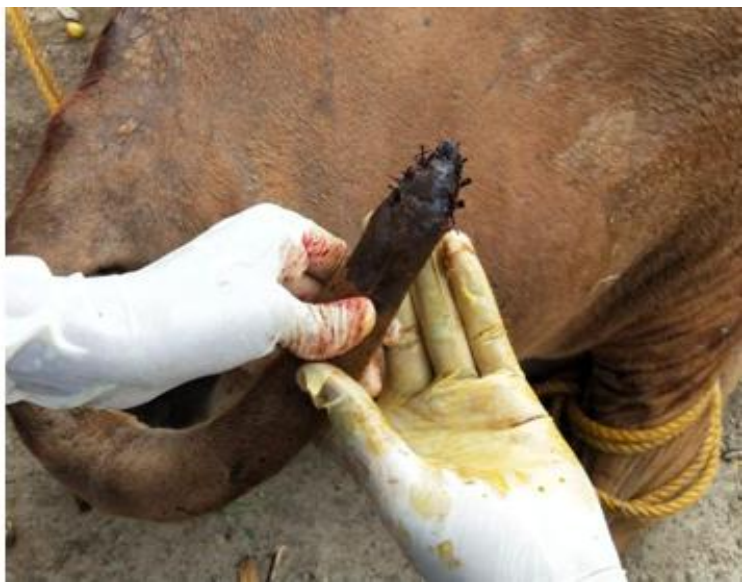


Fig.5 Necrosis in buffalo

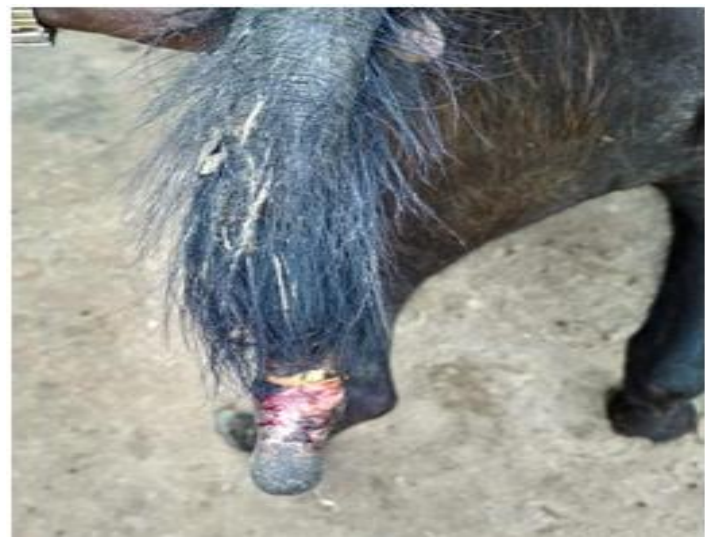

Fig.7 Necrosis at the tip of tail in buffalo

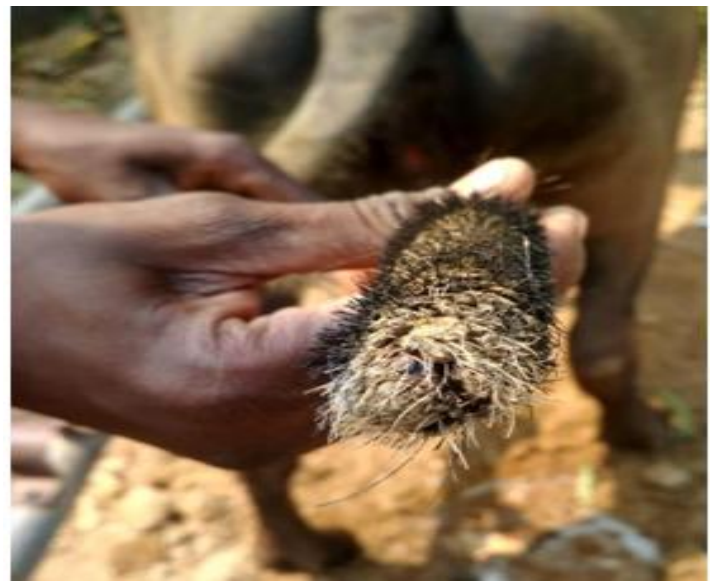

Fig.6 Necrosis and Gangrene in a HF cow

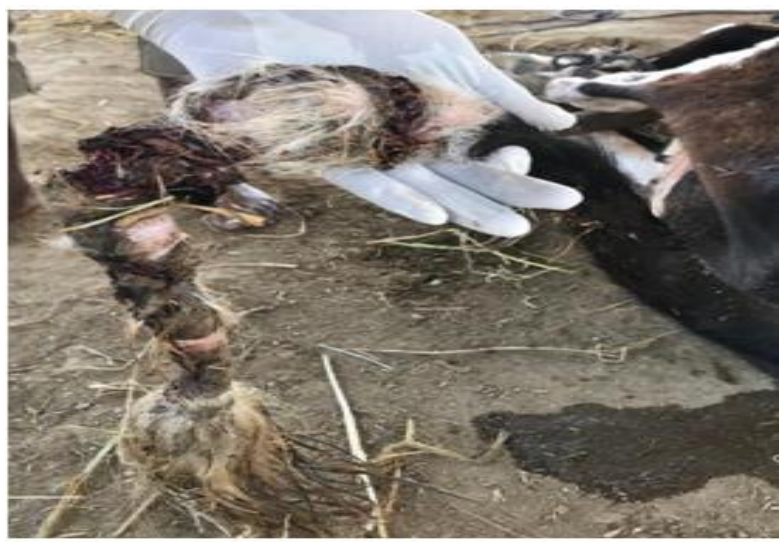

Fig.8 Wound in HF cow

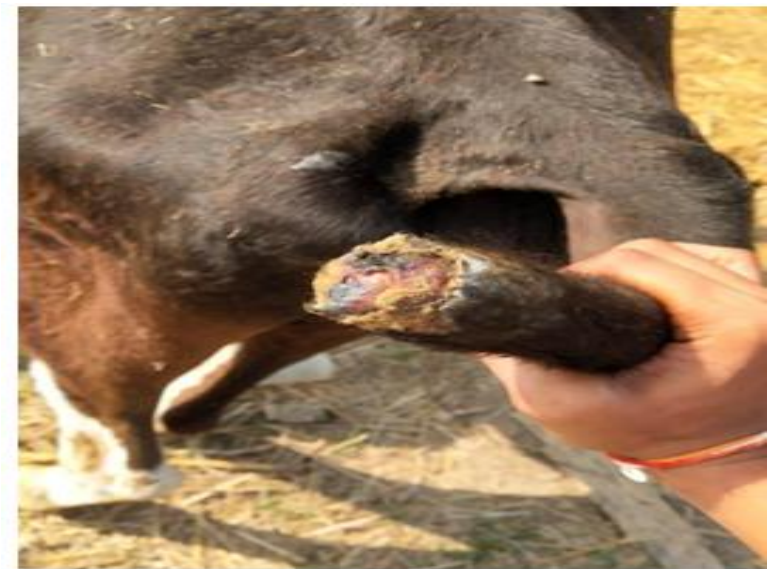

Fig.9 The graphs describes the animals recovery period after the surgery.

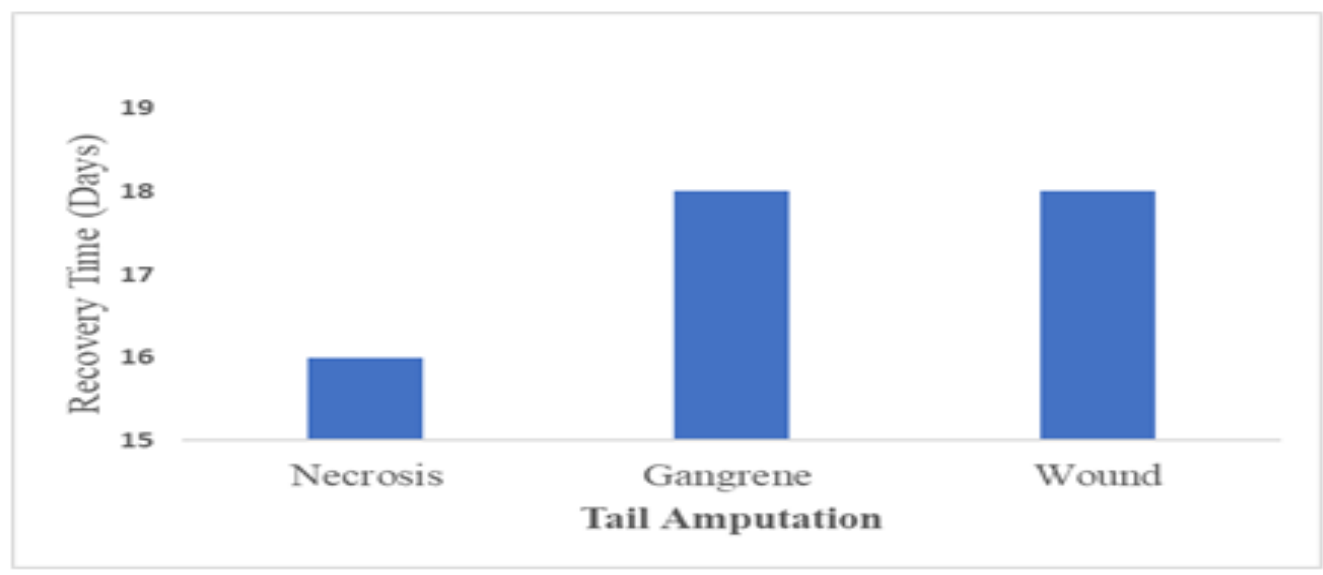

The amputation has been the only effective treatment for this affection (Dhillon and Singh
2003).In Ontario beef feedlot cattle antibiotics and tail amputation used as a therapeutic or 
preventive approach (Drolia et al., 1996). We also used the same surgical and antibiotic medicinal procedure to treat the affection and followed topical antibacterial applications (Ural et al., 2007).

The previous studies advised a cranial amputation of the affected area (Akioye et al., 2010; Nuss and Fiest 2011). Melissa Kaplan's opinion is that the injury towards the tail end led to dry gangrene and proposed amputation of the tail long before the tail was dry and broken. While amputating the tail, the incision should be placed on the healthy zone proximal to the affected area. Hokonohara et al., (2013) treated a tail necrosis by spraying Oxy-G (oxytetracycline - gentatian violet). Satyanarayana et al., (2014) report the successful treatment for necrosis in buffaloes with the application of fomentation in the morning and evening for 15 days \& local streptopencillin@250 mg above the seat of lesion \& topical application of Loraxene ointment.

\section{Gangrene}

Two cows had gangrene from the middle to tip of the tail (Fig), with alopecia was also subjected to amputation. The animals were treated with Parentral Dicrysticin @5gms I/M, Meloxicam @12ml I/M, Histanil @10mlI I/M, Rumeric @10 ml I/M for five days. According to Kaur et al., (2005), chronicselenosis was related to rough haircoat, alopecia, swelling of the coronet, enlargement of the hooves, interdigital lesions, and gangrene at the tip of the tail. The animals recovered on the 18th postoperative day of the surgery. The management of affection varies based on the types of affection. If a disease of the tail does not respond to standard medical treatment, it may be necessary to amputate the tail. In some rare cases, it can be cured with medical treatment(Dillon and Singh,2003) using a powder containing zinc oxide, kaolin, and boric acid applied on the tail to cure the animal of tail gangrene successfully.

\section{Wound}

HF cow had a wound at the tip of the tail due to a traumatic injury (Fig.8)was also amputated. The animal was treated with Ceftriaxone@10mg/Kg B.Wt, Meloxicam @ 10 ml I/MHistanil @ 10ml I/M, Nurocare 10 $\mathrm{ml} \mathrm{I/M} \mathrm{for} \mathrm{5days} \mathrm{following} \mathrm{surgery.} \mathrm{The}$ animal recovered on the 18th day after surgery. Earlier studies reported a degnala disease in buffalo calf treated with long-acting oxytetracycline $(20 \mathrm{mg} / \mathrm{kg} \mathrm{B}$. wt.) and repeated the exact dosage after 72 hours (Kumar, M. 2016). In addition, isofluperidone, B-complex (5ml/buffalo calf) with liver extract $\mathrm{I} / \mathrm{M}$ for five days was administered, along with 30 g/day of penta salts of copper, iron, cobalt, zinc, and manganese. Laxmen Ghimire (2012) reported a case of Degnaladisease in a buffalo and treated with anti-liquor (zinc sulphate) @ $7 \mathrm{ml}$ OD for seven days, long-acting oxytetracycline @ $1 \mathrm{ml} / \mathrm{kg}$ body weight intramuscularly, which was repeated after 72 hours.

The tail amputation is an effective way to treat the affections in Buffaloes and cows. It appears to cure injuries within the three walks weeks following the surgical procedure. It will be of pivotal importance to correlate medicinal approaches in the livestock following tail amputation in the near future.

\section{Acknowledgements}

We are thankful to Sudhakar Deeti, Macquaire University, Syndey, Australia, for revised the manuscript.

\section{References}

Akioye, O., Omobowale, Olaifia and Abiola. 2010. Tail Docking in an African Lion 
(Panthera Leo). Isr.J.Vet.Med., 65(2):75-76.

AlamM. R., Gregory N. G., Uddin M. S., Jabbar, M. A., chodary, Sand Debnath N.C. 2010.Frequency of nose and tail injuries in cattle and water buffalo at Livestock markets in Bangladesh. Animal Welfare, 19:295-300.

Dandapat P, P K Nanda, P K Bandyopadhyay, S Kaushal and A Sikdar, 2011. Prevalence of Deg Nala disease in eastern India and its reproduction in buffaloes by feeding Fusarium oxysporum infested rice straw. Asian Pacif J Trop Med, pp: 54-57.

Dr. Sandhya Rani Dasari and Dr. Aruna Maramulla. Therapeutic management of uterine prolapse in buffalo. The Pharma Innovation Journal 2021; SP10(5): 706-708.

Dhillon, K and Singh, J. 2003 Treatment of gangrene of tail in buffaloes. Punjab veterinary Journal, 3:19-20.

Drolia, H., Leusher, U. A. Meek, A. H., wilcock, B. P. 1992. Tail-tip necrosis in Ontario beef feed lot cattle. Canadian et. J., 32(1):23-29.

Filipov, Z. H., Bodurov, N., Binevand, K., Borisov, I.1986. Necrosis of tail in Buffaloes. Veterinarno Medistinski Nauki, 23:66-71.

Fisher P G 2006. Ferret behavior. Exotic Pet Behavior;163-205.

Fowler M E, 2010. Medicine and Surgery of Camelids. Third Edition, Blackwell Publishing, pp: 576.

George, P. O., Chauran, I. V., Abyas, N. M. 1970.Necrosis of tail in bovine animals. Vet. Rec., 87:231-233.

Ghamire L (2012), A Case Study of Degnala Disease in Buffalo.

Hokonohara S, U M Singh, V C Jha, A Pradhan, S Dev and Ismail Z B (2016). Epidural analgesia in cattle, buffalo \& camels, Veterinary World 9(12):14501455.
Kaur R, S Rampal and H S Sandhu, 2005. clinical and hematological studies on experimentally induced selenosis in crossbred cow calves. Pak Vet J, 25: 127-133.

Khamis Y, H A Hammad, G Hosni, R Salem and G Gamil, 2002. Mycotoxicosis as a cause of tail-tip necrosis in cattle. XXII World Buiatrics Congress Hannover, pp: 18-23.

Kumar, M. (2016). Therapeutic management of Degnala disease in buffalo calf-A case report. International Journal of Agricultural Sciences And Veterinary Medicine (4):6-7.

Madsen E B and K A Nielsen, 1985. A study of tail tip necrosis in young fattening bulls on slatted floors. Nord Vet Med, 37: 349-357.

Manjunatha patil, Narayanashetty sreedhara, J., Dilip Kumar, D. Medical and Surgical Management of Tail affections in buffaloes. Buffalo Bulletin (January to March 2020) Vol.39 No. 1

Melissa Kapplan (2012), Dry Gangrene of Tail and Toe, Cited Nuss K and Feist M(2012), "Tail Amputation for Treatment of Osteomyelitis of the First and Second Coccygeal Vertebrae in a Cow", TierarztlPrax, Vol. 39, No. G, pp. 176-178.

Nuss, L. K. and Fiest, M. 2011.Tail amputation for treatment of osteomyelitis of the first and second coccygeal vertebrae in a cow. Tieraztl. Prax., 39(4):176-178.

R K Mandar, 2003. Clinical and haemtological findings on Degnala disease of a buffalo in eastern Nepal. J Vet Med. Sci. 65:719-722.

Pratheepa, K., karuppiah, A. K., Vijay, K. 2021. Journal of Entomology \& Zoology Studies 2021;9(1):778-780.

Satyanarayana, G., Makenasreenu, Deviprasad, V. and Naidu, G. V. 2014. 
Management of Tail Affections in Buffaloes. Int. J. Agri. Sc\&Vet. Med. P. 27 to 33, ISSN 2320-3730. Vol. 2, No.4, November 2014.

Salib F A and Farghali H A. 2016. Epidemiological, therapeutic \& surgical studies on tail necrosis in Egypt. Inter. J Vet. Sci, 5(2):58-63.

Singh, J and Kumar, A. 2001. The integumentary system, p. 147.in Tyagi,
R. P. S and J. Singh (eds.) Ruminant surgery, $1^{\text {st }}$ ed. CBS Publishers, New Delhi, India.

Ural, K., Alic, D., karakuram, M. C., Aktas, M. S., Hydardedeoglu, A. E., Cingari, C. C. 2007.Tail tip necrosis in beef and dairy cattle \%A report of seven cases in Ankara kafkas. Universities Veteriner Fakultesi Dergisi, 13(2):20320.

\section{How to cite this article:}

Sandhya Rani Dasari, Aruna Maramulla, Samskruthi Guddeti and Sudhakar Deeti. 2021. Management of Tail Affections in Cows and Buffaloes. Int.J.Curr.Microbiol.App.Sci. 10(06): 458-466. doi: https://doi.org/10.20546/ijcmas.2021.1006.049 